\title{
Erratum to: Naturally occurring Vpr inhibitors from medicinal plants of Myanmar
}

\author{
Nwet Nwet Win ${ }^{1,2} \cdot$ Hla Ngwe $^{2} \cdot$ Ikuro Abe $^{3} \cdot$ Hiroyuki Morita ${ }^{1}$
}

Published online: 12 September 2017

(C) The Japanese Society of Pharmacognosy and Springer Japan KK 2017

\section{Erratum to: J Nat Med DOI 10.1007/s11418-017-1104-7}

The article Naturally occurring $\mathrm{Vpr}$ inhibitors from medicinal plants of Myanmar, written by Nwet Nwet Win, Hla Ngwe, Ikuro Abe and Hiroyuki Morita, was originally published electronically on the publisher's internet portal (currently SpringerLink) on 5 July 2017 without open access.

With the author(s)' decision to opt for Open Choice the copyright of the article changed on 05 July 2017 to (C) The
Author(s) 2017 and the article is forthwith distributed under the terms of the Creative Commons Attribution 4.0 International License (http://creativecommons.org/licen ses/by/4.0/), which permits use, duplication, adaptation, distribution and reproduction in any medium or format, as long as you give appropriate credit to the original author(s) and the source, provide a link to the Creative Commons license and indicate if changes were made.

The online version of the original article can be found under doi:10.1007/s11418-017-1104-7.

Nwet Nwet Win

nwetwin2012@gmail.com

$\triangle$ Hiroyuki Morita

hmorita@inm.u-toyama.ac.jp

1 Institute of Natural Medicine, University of Toyama, 2630-

Sugitani, Toyama 930-0194, Japan

2 Department of Chemistry, University of Yangon,

Yangon 11041, Myanmar

3 Graduate School of Pharmaceutical Sciences, The University of Tokyo, 7-3-1 Hongo, Bunkyo-ku, Tokyo 113-0033, Japan 